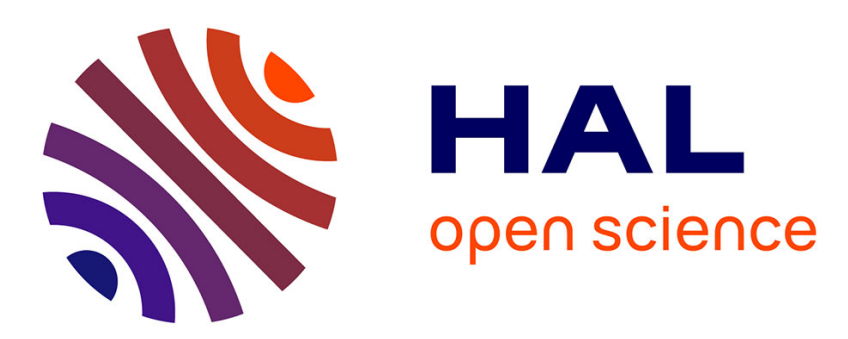

\title{
Influence of transformation temperature on microtexture formation associated with alpha precipitation at beta grain boundaries in a beta metastable titanium alloy
}

Matthieu Salib, Julien da Costa Teixeira, L. Germain, Erol Lamielle, N. Gey, Elisabeth Aeby-Gautier

\section{To cite this version:}

Matthieu Salib, Julien da Costa Teixeira, L. Germain, Erol Lamielle, N. Gey, et al.. Influence of transformation temperature on microtexture formation associated with alpha precipitation at beta grain boundaries in a beta metastable titanium alloy. Acta Materialia, 2013, 61 (10), pp.3758-3768. 10.1016/j.actamat.2013.03.007 . hal-01293814

\section{HAL Id: hal-01293814 \\ https://hal.science/hal-01293814}

Submitted on 12 Dec 2019

HAL is a multi-disciplinary open access archive for the deposit and dissemination of scientific research documents, whether they are published or not. The documents may come from teaching and research institutions in France or abroad, or from public or private research centers.
L'archive ouverte pluridisciplinaire HAL, est destinée au dépôt et à la diffusion de documents scientifiques de niveau recherche, publiés ou non, émanant des établissements d'enseignement et de recherche français ou étrangers, des laboratoires publics ou privés. 


\title{
Influence of transformation temperature on microtexture formation associated with $\alpha$ precipitation at $\beta$ grain boundaries in a $\beta$ metastable titanium alloy
}

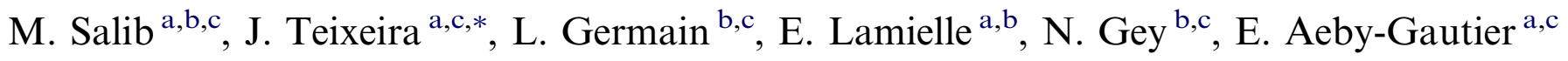 \\ a Institut Jean Lamour (IJL), SI2M Dept., CNRS UMR 7198, Université de Lorraine, Parc de Saurupt, CS 50840, F-54011 Nancy CEDEX, France \\ ${ }^{\mathrm{b}}$ Laboratoire d'Etude des Microstructures et de Mécanique des Matériaux (LEM3), CNRS UMR 7239, Université de Lorraine, Île du Saulcy, \\ F-57045 Metz CEDEX 1, France \\ ${ }^{\mathrm{c}}$ Laboratory of Excellence for Design of Alloy Metals for Low-mass Structures ('DAMAS' Labex), Université de Lorraine, France
}

\begin{abstract}
The influence of transformation temperature on microtexture development associated with $\alpha$ precipitation at $\beta / \beta$ grain boundaries (GB) in the near- $\beta$ Ti17 alloy was studied using electron backscatter diffraction and considering isothermal treatments. For the alloy studied and the temperature range considered, decreasing the transformation temperature decreased the local microtexture strength within each prior $\beta$ grain because of a larger number of $\alpha_{\mathrm{WGB}}$ colonies (standing for $\alpha$ Widmanstätten GB) formed per $\beta$ grain, each colony increasing by one the number of $\alpha$ orientations inside each prior $\beta$ grain. This larger number of $\alpha_{\mathrm{WGB}}$ colonies was a consequence of faster formation along $\beta / \beta \mathrm{GB}$ of their precursors, the allotriomorphic $\alpha_{\mathrm{GB}}$ grains (standing for $\alpha$-GB) at lower transformation temperatures, as evidenced by detailed examination of the first stages of $\alpha_{\mathrm{GB}}$ formation. $\alpha_{\mathrm{GB}}$ crystallographic orientations frequently fol-

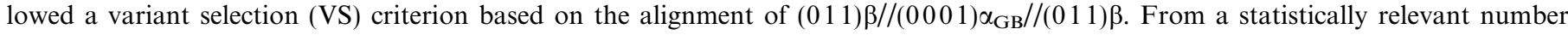
of observations, VS was found to be more frequent at a lower transformation duration and a lower temperature, but the effect was not significant enough to influence the final $\alpha$ microtexture, considered at the scale of one prior $\beta$ grain. $\alpha_{\mathrm{GB}}$ grains that followed the VS criterion emitted two $\alpha_{\mathrm{WGB}}$ colonies on either side of the $\beta / \beta$ GB more frequently than those with no particular orientation.
\end{abstract}

Keywords: Titanium; Microstructure; Microtexture; Phase transformation; Electron backscatter diffraction

\section{Introduction}

Most studies on titanium alloys dealing with the microstructure and local texture development associated with the $\beta \rightarrow \alpha+\beta$ transformation focus either on the inherited morphology and associated kinetics [1-9] or the crystallographic aspects [10-17]. The present work proposes to link these two.

During cooling of titanium alloys from the $\beta$ field, the $\alpha$ phase first forms at $\beta / \beta$ grain boundaries (GB). This $\alpha_{\mathrm{GB}}(\alpha$

\footnotetext{
* Corresponding author at: Institut Jean Lamour (IJL), SI2M Dept., CNRS UMR 7198, Université de Lorraine, Parc de Saurupt, CS 50840, F54011 Nancy CEDEX, France. Tel.: +33 (0)3 835842 25; fax +33 (0)3 83 584056.

E-mail address: julien.teixeira@mines.inpl-nancy.fr (J. Teixeira).
}

GB) morphology consists of nearly continuous $\alpha$ phase layers along $\beta / \beta$ GB. Then, Widmanstätten colonies $\left(\alpha_{\mathrm{WGB}}\right)$ form from those new $\alpha_{\mathrm{GB}} / \beta$ interfaces [1]. They consist of parallel side plates of close orientation separated by remaining layers of $\beta$ matrix enriched in $\beta$-stabilizing elements. Within a colony, there is a tendency to reach the thermodynamic equilibrium values of the respective volume fractions and chemical compositions of both $\alpha$ and enriched $\beta$ phases. Each $\alpha_{\mathrm{WGB}}$ colony needs a parent $\alpha_{\mathrm{GB}}$ grain to form (they never form directly on $\beta / \beta \mathrm{GB}$ ). Eventually, if the transformation is not complete and the transformation conditions are achieved, intragranular nucleation of $\alpha$ occurs, leading to a plate morphology identified as the $\alpha_{\mathrm{WI}}$ morphology (standing for Widmanstätten 
Table 1

Chemical composition of the Ti17 alloy studied, measured at top and bottom of the billet.

\begin{tabular}{lllllll}
\hline & $\mathrm{Al}$ & $\mathrm{Cr}$ & $\mathrm{Mo}$ & $\mathrm{Sn}$ & $\mathrm{Zr}$ & $\mathrm{O}_{2}(\mathrm{ppm})$ \\
\hline Top & 5.03 & 3.99 & 4.03 & 1.99 & 1.97 & 1225 \\
Bottom & 5.01 & 4.13 & 3.90 & 2.05 & 2.01 & 1205 \\
\hline
\end{tabular}

intragranular). This experimental knowledge has recently allowed the modeling of these phase transformations, based either on isothermal (IT) diagrams (JohnsonMehl-Avrami-Kolmogorov description $[6,18]$ ) or on mesoscale approaches based on thermodynamic and diffusion data and describing nucleation and growth processes [1921]. Using specific models for each morphology makes it possible to predict their growth kinetics and chemical composition as a function of temperature evolution.

The $\beta \rightarrow \alpha+\beta$ phase transformation follows the Burgers orientation relationship (BOR), which implies the parallelism of dense planes and direction of both phases: $(011)_{\beta} / /(0001)_{\alpha},[11-1]_{\beta} / /[11-20]_{\alpha}$. One $\beta$ orientation can thus give rise to 12 crystallographic $\alpha$ orientations, called variants. Concerning the $\alpha_{\mathrm{WI}}$ grains, the 12 variants occur with the same frequency [22]. The $\alpha_{\mathrm{GB}}$ grains are mostly in BOR, with only one of the two $\beta$ grains separated by the $\beta / \beta$ GB $[12-14,16]$. The variant taken by $\alpha_{\mathrm{GB}}$ is not random; it depends on the crystallographic parameters of the $\beta / \beta$ GB. This phenomenon is called variant selection (VS) [23]. The selection of $\alpha_{\mathrm{GB}}$ variants has a direct influence on the $\alpha$ texture obtained at the end of cooling $[12,24]$. Indeed, the $\alpha_{\mathrm{WGB}}$ colonies inherit the orientations taken by their $\alpha_{\mathrm{GB}}$ parent grains. Therefore, it is possible to obtain very large areas of the parent $\beta$ grain with a single orientation of the $\alpha$ phase, which can be detrimental to mechanical properties $[12,25]$.

Better control of the mechanical properties can be achieved by studying the $\alpha$ texture resulting from the $\beta \rightarrow \alpha+\beta$ phase transformation. This has been done extensively at a macroscopic scale (e.g., Ref. [11]) or locally using the electron backscatter diffraction (EBSD) technique [12]. These previous studies focused only on the influence of the $\beta$ grains orientations ( $\beta$ texture) on the $\alpha$ phase texture. Now one can also use the EBSD technique to start studying the influence of thermal treatment parameters (e.g., cooling rate) on the development of the microtexture, as attempted very recently [26]. First, one has to establish the role of the transformation processes (phase growth, morphologies) and associated kinetics. Little is known on the detailed sequence of events associated with the microtexture construction, because most observations in the literature were done after completion of phase transformation. Second, possible VS influence on final microtexture has to be studied. In particular, it is not known whether the phase transformation temperature can modify the variants selected preferentially, i.e., the nature of VS criteria and their frequency of occurrence.

The purpose of this study is to achieve an experimental investigation of the influence of transformation temperature on $\alpha$ microtexture development. The study was carried out considering a $\beta$ metastable alloy (Ti17) whose microstructures have been studied extensively [1-3,18-21], but without considering crystallographic orientations. The focus was on $\alpha$ precipitation at $\beta$ GB giving rise to VS. The $\alpha$ microtexture was characterized using the EBSD technique. The VS was estimated by counting the number of $\alpha_{\mathrm{WGB}}$ variants over a statistical number of prior $\beta$ grains. The influence on the microtexture strength of two distinct features of the $\alpha$ precipitation sequence at $\beta / \beta$ GB was established: First, the final number of $\alpha_{\text {WGB }}$ colonies per prior $\beta$ grain, which depends on the phase transformation processes ( $\alpha_{\mathrm{GB}}$ and $\alpha_{\mathrm{WGB}}$ formation). Increasing this number weakened the microtexture. Second, VS was considered, in so far as it can reduce the number of $\alpha$ orientations and strengthen the microtexture. Influence of phase transformation temperature on both aspects was examined. After detailing the experimental method, results are presented according to the chronology of the precipitation sequence of $\alpha$ on $\beta / \beta \mathrm{GB}$, and will be discussed in a later section.

Table 2

Thermal treatments and microtexture analysis performed with EBSD.

\begin{tabular}{lllllllll}
\hline $\begin{array}{l}T \\
\left({ }^{\circ} \mathrm{C}\right)\end{array}$ & Duration & $\begin{array}{l}\text { Precipitation } \\
\text { sequence }\end{array}$ & $\begin{array}{l}\text { Equilibrium } \alpha \text { volume } \\
\text { fraction }[2](\%)\end{array}$ & $\begin{array}{l}\alpha \text { Volume } \\
\text { fraction }(\%)\end{array}$ & $\begin{array}{l}\text { Fraction of GB } \\
\text { decoration by } \alpha_{\mathrm{GB}} \mathrm{b}(\%)\end{array}$ & $\begin{array}{l}\text { Technique } \\
\text { of analysis }\end{array}$ & $\begin{array}{l}\text { EBSD step } \\
\text { size }(\mu \mathrm{m})\end{array}$ & $\begin{array}{l}\text { No. of } \alpha_{\mathrm{GB}} \text { grains } \\
\text { analyzed with EBSD }\end{array}$ \\
\hline 830 & $16 \mathrm{~h}$ & Complete & 27 & 27 & 91 & EBSD & 1 & 200 \\
800 & $200 \mathrm{~s}$ & $\alpha_{\mathrm{GB}}$ & 35 & 1 & 12 & OM & - & - \\
& $700 \mathrm{~s}$ & & 4 & 65 & EBSD & 0.5 & 107 \\
& $1 \mathrm{~h}$ & $\alpha_{\mathrm{WGB}}$ & & 17 & 81 & EBSD & 0.5 & 450 \\
& $6 \mathrm{~h}$ & Complete & & 35 & 94 & EBSD & 0.5 & 168 \\
750 & $100 \mathrm{~s}$ & $\alpha_{\mathrm{GB}}$ & 45 & 0 & 7.9 & OM & - & - \\
& $700 \mathrm{~s}$ & $\alpha_{\mathrm{WGB}}$ & & 6.5 & 81 & EBSD & 0.4 & 204 \\
& $6800 \mathrm{~s}$ & Complete & & 45 & 97 & EBSD & 0.4 & 158 \\
\hline
\end{tabular}

${ }^{a}$ Estimated from previous phase transformation kinetics measurements [1-3].

$b$ Total length of $\alpha_{\mathrm{GB}}$ grains divided by total length of $\beta / \beta \mathrm{GB}$. 


\section{Experimental}

\subsection{Material}

Cylindrical specimens $3 \mathrm{~mm}$ in diameter and $30 \mathrm{~mm}$ in length were spark-machined (electrical discharge machining) from a billet of Ti17 alloy manufactured by TIMETSavoie. Its composition is shown in Table 1. A $\beta$ transus of $880{ }^{\circ} \mathrm{C}$ was measured through electrical resistivity [27] and confirmed by high energy X-ray diffraction [3].

\subsection{Thermal treatments}

The samples were first solution-treated at $920^{\circ} \mathrm{C}$ in the $\beta$ phase field for $30 \mathrm{~min}$ to obtain a homogeneous $\beta$ grain size of $\sim 200 \mu \mathrm{m}$. Then IT treatments in the $\alpha+\beta$ field (Table 2) were carried out under secondary vacuum. Finally, the high-temperature $\alpha / \beta$ microstructure was quenched in less than $10 \mathrm{~s}$ by blowing helium gas. On the basis of previous characterizations of IT phase transformation kinetics [1-3], the transformation temperatures and durations were chosen so that only $\alpha_{\mathrm{GB}}$ and $\alpha_{\mathrm{WGB}}$ were formed.

Three transformation temperatures were chosen $\left(750{ }^{\circ} \mathrm{C}, 800{ }^{\circ} \mathrm{C}\right.$ and $\left.830^{\circ} \mathrm{C}\right)$ to consider the influence of the phase transformation driving force. The following durations were selected corresponding to different stages of the $\alpha$ precipitation sequence: $200 \mathrm{~s}$ and $700 \mathrm{~s}$ at $800{ }^{\circ} \mathrm{C}$, $25 \mathrm{~s}$ and $100 \mathrm{~s}$ at $750{ }^{\circ} \mathrm{C}$ to examine $\alpha_{\mathrm{GB}}$ formation along $\beta / \beta \mathrm{GB} ; 1 \mathrm{~h}$ at $800^{\circ} \mathrm{C}$ and $700 \mathrm{~s}$ at $750{ }^{\circ} \mathrm{C}$, at the beginning of $\alpha_{\mathrm{WGB}}$ colonies formation; $16 \mathrm{~h}$ at $830^{\circ} \mathrm{C}, 6 \mathrm{~h}$ at $800^{\circ} \mathrm{C}$ and $6800 \mathrm{~s}$ at $750^{\circ} \mathrm{C}$, at phase transformation completion - the equilibrium $\alpha$ amount has nearly been reached, and there is no more microstructure evolution.

\subsection{Microstructure characterization}

The observation techniques used for each treatment are specified in Table 2. Most measurements were done using scanning electron microscopy (SEM) micrographs obtained in combination with EBSD experiments (see next section), except for the shortest durations of IT treatment, for which optical microscopy was used. For optical microscopy, the samples were mechanically polished and then etched using Kroll's reagent. As shown in Table 2, the $\alpha_{\mathrm{GB}}$ nucleation and growth stage correspond to a negligible $\alpha$ volume fraction and partial $\beta / \beta$ GB decoration by $\alpha_{\mathrm{GB}}$. At the $\alpha_{\mathrm{WGB}}$ growth stage, the GB decoration is almost complete, and the $\alpha$ phase volume fraction is more significant.

Typical optical micrographs are shown in Fig. 1. The $800^{\circ} \mathrm{C}-1 \mathrm{~h}$ microstructure exhibits both $\alpha_{\mathrm{GB}}$ and $\alpha_{\mathrm{WGB}}$ morphologies. Different degrees of transformation, characterized by the size and amount of $\alpha_{\mathrm{GB}}$ grains and $\alpha_{\mathrm{WGB}}$ colonies, have been reached on each $\beta / \beta$ GB. The $800^{\circ} \mathrm{C}-$ $700 \mathrm{~s}$ microstructure exhibits only a few $\alpha_{\mathrm{GB}}$ grains. Finally, the $750{ }^{\circ} \mathrm{C}-700 \mathrm{~s}$ microstructure is similar to the $800{ }^{\circ} \mathrm{C}-1 \mathrm{~h}$ one, with finer $\alpha_{\mathrm{GB}}$ grains and less developed colonies of $\alpha_{\mathrm{WGB}}$. Microstructures for shorter IT treatment are shown in Section 3.1.1, and the aspect for phase transformation completion can be found, for instance, in Ref. [2].

\subsection{Microtexture characterization}

EBSD analyses were performed on the most relevant samples (see Table 2). Samples were first mechanically and then electrolytically polished (in $80 \%$ methanol- $20 \%$ perchloric acid, applying $17 \mathrm{~V}, 2 \mathrm{~A}, 20 \mathrm{~s}, 3^{\circ} \mathrm{C}$ ). Crystallographic orientation maps were acquired by SEM with JEOL 6490 and FEI Quanta 600 FEG instruments, both equipped with NordlysF cameras and HKL software from Oxford Instruments. Depending on the sample, different maps were acquired and analyzed until at least $200 \beta / \beta$ GB had been sampled, in order to obtain statistically relevant data. The maps were obtained with a step size of 0.4 or $0.5 \mu \mathrm{m}$, indexing both $\beta$ and $\alpha$ phases.

The orientations in the maps and pole figures are colored according to the code of the standard triangle (each color depends on the projection of a macroscopic direction in the crystal reference frame). With this code, different colors indicate different crystallographic orientations, but the inverse is not true.

GB characteristics such as length, transformed fraction, misorientation, VS mechanism criteria, presence of $\alpha_{\mathrm{GB}} /$ $\alpha_{\mathrm{WGB}}$, misorientation were systematically inventoried by hand. It was verified that the observations were statistically relevant by making sure that increasing the number of measurements did not change further the average value of the examined parameters.

\section{Results}

\subsection{Precipitation of $\alpha_{G B}$}

Different observations (Figs. 2 and 3) showed that decoration of $\beta / \beta$ GB by $\alpha_{\mathrm{GB}}$ grains was progressive at both transformation temperatures. In this section, the rate of $\alpha_{\mathrm{GB}}$ formation is further analyzed by considering the formation process along the $\beta / \beta \mathrm{GB}$, focusing on the first stages in particular.

\subsection{1. $\alpha_{G B}$ Grains number per $\beta / \beta G B$}

Within each prior $\beta$ grain, the numbers of $\alpha_{\mathrm{GB}}$ grains and of $\alpha_{\mathrm{WGB}}$ colonies are closely related, because each colony needs one precursor $\alpha_{\mathrm{GB}}$ grain to form. Hence, measuring the number of $\alpha_{\mathrm{GB}}$ is important for understanding the microtexture development. Such measurements are used in Section 3.3.2 to interpret the variation of the number of $\alpha_{\mathrm{WGB}}$ colonies per $\beta$ grain with transformation conditions. The average number of $\alpha_{\mathrm{GB}}$ grains per $\beta / \beta$ GB was counted, denoted $N_{\mathrm{GB}}$. A statistically relevant number of $\alpha_{\mathrm{GB}}$ grains were inventoried, using EBDS maps as in Fig. 3, in order to establish the influence of phase transformation temperature and duration on $N_{\mathrm{GB}}$. 
$N_{\mathrm{GB}}$ measurements are shown in Table 3. Noticeable is the limited $N_{\mathrm{GB}}$ variation with transformation duration, which increases from 1.7 to 2.4 at $750{ }^{\circ} \mathrm{C}$ and 1.8 to 1.9 at $800{ }^{\circ} \mathrm{C}$. Considering the influence of the phase transformation temperature, it is interesting to observe that $N_{\mathrm{GB}}$ was not very different between 830 and $750{ }^{\circ} \mathrm{C}$, despite the different driving force. At phase transformation completion, $N_{\mathrm{GB}}$ was equal to 1.8 at $830{ }^{\circ} \mathrm{C}$ and 2.4 at $750{ }^{\circ} \mathrm{C}$. For lower transformation durations at 750 and $800^{\circ} \mathrm{C}$, measured $N_{\mathrm{GB}}$ values were also similar.

In order to explain the low $N_{\mathrm{GB}}$ values $(\sim 2)$ and their limited variation with both transformation temperature and transformation duration, the first stages of $\alpha_{\mathrm{GB}}$ grain formation were considered. Observing the microstructure after a short transformation duration $\left(200 \mathrm{~s}\right.$ at $800{ }^{\circ} \mathrm{C}$
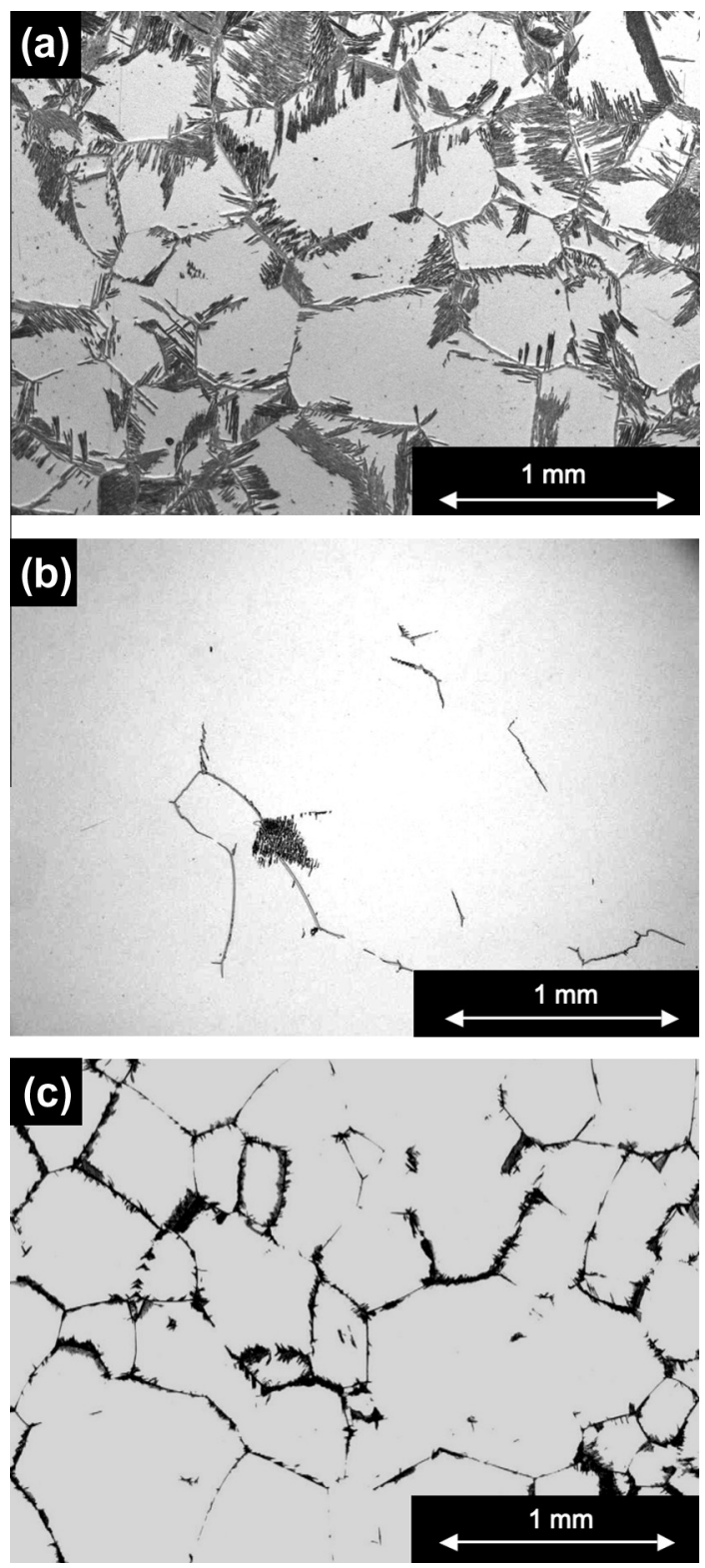

Fig. 1. Micrograph of sample at: (a) $800{ }^{\circ} \mathrm{C}-1 \mathrm{~h}$; (b) $800{ }^{\circ} \mathrm{C}-700 \mathrm{~s}$; (c) $750{ }^{\circ} \mathrm{C}-700 \mathrm{~s}$.
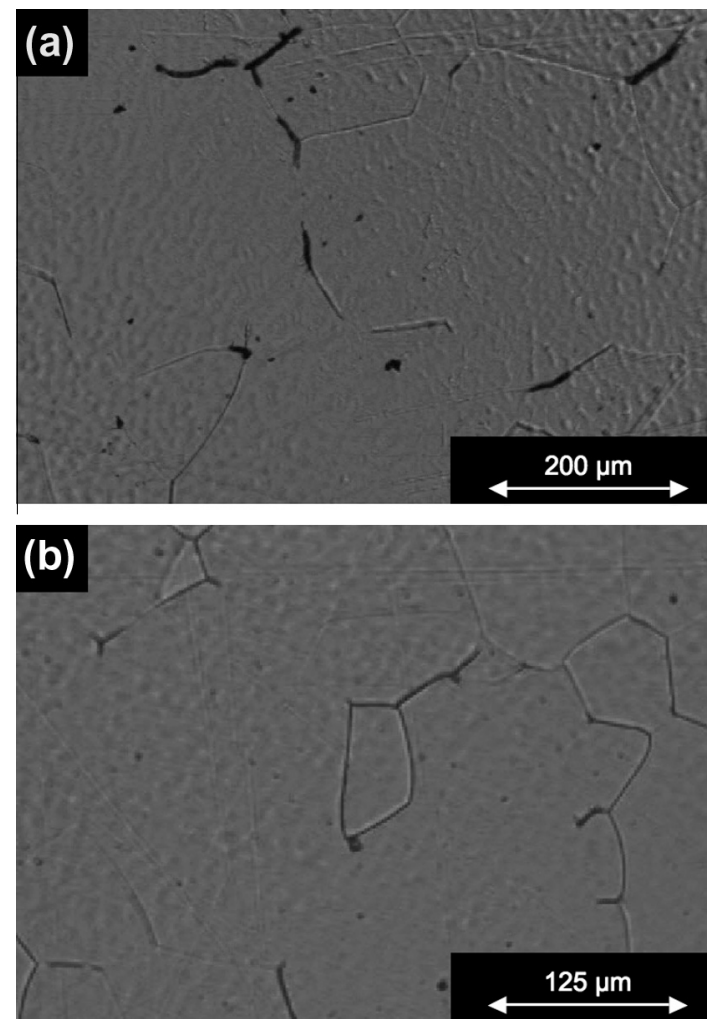

Fig. 2. Optical micrographs: (a) $800{ }^{\circ} \mathrm{C}-200 \mathrm{~s}$; (b) $750{ }^{\circ} \mathrm{C}-100 \mathrm{~s}$.

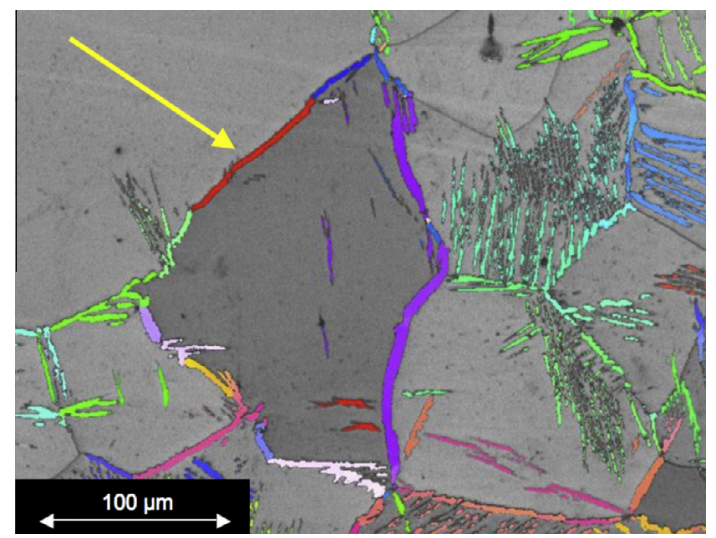

Fig. 3. EBSD orientation map of the $800{ }^{\circ} \mathrm{C}-1 \mathrm{~h}$ microstructure. Arrowed $\alpha_{\mathrm{GB}}$ isolated from $\mathrm{TJ}$.

and $100 \mathrm{~s}$ at $750{ }^{\circ} \mathrm{C}$ ) enabled the first $\alpha_{\mathrm{GB}}$ grains formed to be located. The optical micrograph in Fig. 2a shows that, at a transformation temperature of $800^{\circ} \mathrm{C}$, the first $\alpha_{\mathrm{GB}}$ grains were always connected to a triple junction (TJ). However, for a phase transformation temperature of $750{ }^{\circ} \mathrm{C}$ (Fig. 2b), the $\alpha_{\mathrm{GB}}$ grains were too thin to confirm this observation without uncertainty in some cases, even using SEM.

One can nevertheless deduce the following simple $\alpha_{\mathrm{GB}}$ formation sequence from these observations: precipitation starts at TJ, followed by $\alpha_{\mathrm{GB}}$ growth along the $\beta / \beta$ GB planes, leading to large $\alpha_{\mathrm{GB}}$ grains like those in Fig. 3. This 
Table 3

No. of $\alpha_{\mathrm{GB}}$ grains and $\alpha_{\mathrm{WGB}}$ colonies per $\beta$ grain.

\begin{tabular}{|c|c|c|c|c|c|}
\hline & \multicolumn{2}{|c|}{$750^{\circ} \mathrm{C}$} & \multicolumn{2}{|c|}{$800{ }^{\circ} \mathrm{C}$} & \multirow{2}{*}{$\begin{array}{l}830^{\circ} \mathrm{C} \\
16 \mathrm{~h}\end{array}$} \\
\hline & $700 \mathrm{~s}$ & $6800 \mathrm{~s}$ & $1 \mathrm{~h}$ & $6 \mathrm{~h}$ & \\
\hline$\alpha$ Decorated GB proportion $^{\mathrm{a}}(\%)$ & 81 & 97 & 81 & 94 & 91 \\
\hline$N_{\mathrm{GB}}$ & 1.7 & 2.4 & 1.8 & 1.9 & 1.8 \\
\hline$N_{\text {WGB }}$ & 2.75 & 7.7 & 2.8 & 4.4 & 3.6 \\
\hline
\end{tabular}

${ }^{\text {a }}$ Total length of $\alpha_{\mathrm{GB}}$ grains divided by total length of $\beta / \beta$ GB.

sequence certainly occurred at $800{ }^{\circ} \mathrm{C}$ and probably at $750{ }^{\circ} \mathrm{C}$. This sequence explains the low $N_{\mathrm{GB}}$ values measured ( $\sim 2)$ : nucleation of $\alpha$ was restricted to a very limited number of sites located at TJ, or perhaps more restrictively at $\beta$ quadruple points (QP, corners). This sequence may also explain why $N_{\mathrm{GB}}$ did not vary significantly with the transformation temperature. At $830^{\circ} \mathrm{C}$, the nucleation driving force was already large enough to enable $\alpha$ nucleation on almost all available nucleation sites, and decreasing the transformation temperature to 800 or $750{ }^{\circ} \mathrm{C}$ did not activate many additional nucleation sites. $N_{\mathrm{GB}}$ is stable with transformation duration, because the nucleation sites were saturated before the transformation durations considered.

It is worth mentioning that a very different $\alpha_{\mathrm{GB}}$ formation sequence has been proposed in other studies [4,17]: large $\alpha_{\mathrm{GB}}$ grains like those of Fig. 3 are believed to result from the impingement by growth of several fine $\alpha$ precipitates that nucleated separately in the middle of the $\beta / \beta$ GB plane. These initially separate precipitates are believed to have the same crystallographic orientation because of strong VS at $\beta / \beta$ GB. The observations in Refs. $[4,17]$ should not be generalized too readily, because the authors considered alloy compositions, transformation temperatures and rate of diffusion different from those of present study. For instance in Ref. [17], a transformation temperature of $660^{\circ} \mathrm{C}$ was considered. The slower diffusion of the alloying elements is likely to have impeded the $\beta / \beta$ GB decoration by $\alpha_{\mathrm{GB}}$ diffusional growth, leaving enough time, in this case, for $\alpha$ to nucleate in the middle of the GB.

The key difference with the present proposed sequence is that, according to Refs. [4,17], the $\alpha$ phase can nucleate in the middle of the $\beta / \beta$ GB planes. For the transformation conditions considered, $\alpha$ grains at the middle of a $\beta / \beta$ plane and disconnected from a TJ were almost never observed. Only a few exceptions were observed after longer transformation durations, where some $\alpha_{\mathrm{GB}}$ grains can be considered isolated from a TJ, as shown by the arrow in Fig. 3. However, recent 3D characterization of the microstructure [28] revealed that the $\alpha_{\mathrm{GB}}$ grains grew, with ramifications. Apparently isolated $\alpha_{\mathrm{GB}}$ may, in fact, be the intersection of these ramifications with the observation plane.

The micrographs at short durations in Fig. 2 provide sufficient evidence that $\alpha$ nucleation was restricted to $\beta$ $\mathrm{TJ}$ or perhaps only $\mathrm{QP}$, at least at $800{ }^{\circ} \mathrm{C}$ and probably at $750{ }^{\circ} \mathrm{C}$. Fig. 2 is only one example of a statistical number of micrographs that were carefully examined. The low variation in $N_{\mathrm{GB}}$ shows that the transformation temperature has an effect mainly on the kinetics of $\alpha_{\mathrm{GB}}$ formation (as detailed in the next section), i.e., the number of $\alpha_{\mathrm{GB}}$ precursors for $\alpha_{\mathrm{WGB}}$ colonies can be considered as nearly constant.

\subsubsection{Growth along the GB planes}

Table 2 illustrates the fact that the $\alpha_{\mathrm{GB}}$ grains decorated the $\beta / \beta$ GB progressively (i.e., there was no "immediate" wetting). For instance, at $800{ }^{\circ} \mathrm{C}$, the fraction of GB decoration by $\alpha_{\mathrm{GB}}$ increased from $12,65,81$ and $94 \%$ after $200 \mathrm{~s}, 700 \mathrm{~s}, 1 \mathrm{~h}$ and $6 \mathrm{~h}$ of transformation. An analysis of the effect of the $\beta / \beta$ GB misorientation angle $\theta$, not detailed here, revealed that the $\alpha_{\mathrm{GB}}$ growth was faster on high angle GB $\left(\theta>15^{\circ}\right)$ than on low angle GB $\left(\theta<15^{\circ}\right)$. Hence, the $\beta / \beta$ GB energy influenced the $\alpha_{\mathrm{GB}}$ growth rate.

The effect of the transformation temperature on the rate of $\alpha_{\mathrm{GB}}$ formation shows that the kinetics was faster at $750{ }^{\circ} \mathrm{C}$ than at $800^{\circ} \mathrm{C}$. The time to fill $\sim 80 \%$ of the $\beta / \beta$ GB with $\alpha_{\mathrm{GB}}$ grains was $700 \mathrm{~s}$ at $750^{\circ} \mathrm{C}$ and $1 \mathrm{~h}$ at $800^{\circ} \mathrm{C}$ (Table 2). By dividing an approximate $\beta / \beta$ GB length $(\sim 100 \mu \mathrm{m})$ by these durations, a crude $\alpha_{\mathrm{GB}}$ growth rate along the GB is estimated at $14 \times 10^{-8} \mathrm{~m} \mathrm{~s}^{-1}$ and $2.8 \times 10^{-8} \mathrm{~m} \mathrm{~s}^{-1}$ at 750 and $800^{\circ} \mathrm{C}$. Faster $\alpha_{\mathrm{GB}}$ growth at $750{ }^{\circ} \mathrm{C}$ than at $800^{\circ} \mathrm{C}$ is consistent with previous studies on $\alpha_{\mathrm{WGB}}$ morphology [19], which clearly established the diffusion-controlled growth of $\alpha$. According to modeling [19-21], the $\alpha_{\mathrm{WGB}}$ platelets' growth rate at 750 and $800^{\circ} \mathrm{C}$ was equal to $2.0 \times 10^{-8} \mathrm{~m} \mathrm{~s}^{-1}$ and $1.0 \times 10^{-8}$. $\mathrm{m} \mathrm{s}^{-1}$. Growth rate orders of magnitude are thus similar for $\alpha_{\mathrm{GB}}$ (along the GB) and $\alpha_{\mathrm{WGB}}$, though with higher growth rates for $\alpha_{\mathrm{GB}}$ and a bigger difference between $\alpha_{\mathrm{GB}}$ and $\alpha_{\mathrm{WGB}}$ at $750^{\circ} \mathrm{C}$. This bigger difference will have consequences for further evolution of the microstructure associated with the development of the $\alpha_{\mathrm{WGB}}$ colonies, which is highlighted in Section 3.3.2.

\subsection{Orientation of $\alpha_{G B}$; variant selection}

The present results confirm that, in the vast majority of cases, the $\alpha_{\mathrm{GB}}$ grains are in BOR, with only one of the two $\beta$ grains adjoining the $\beta / \beta$ GB (Table 4 ), in accordance with numerous previous works. No $\alpha_{\mathrm{GB}}$ grain was found to respect the exact BOR with both grains at the boundary,

\section{Table 4}

Proportion of $\alpha_{\mathrm{GB}}$ grains verifying the BOR with the $\beta$ grains in contact: maximum deviation to BOR considered for the statistics, $5^{\circ}$.

\begin{tabular}{|c|c|c|c|}
\hline \multirow[t]{2}{*}{ Thermal treatment } & \multicolumn{3}{|c|}{$\begin{array}{l}\text { No. of adjoining } \beta \text { grains respecting the BOR with } \\
\alpha_{\mathrm{GB}} \text { grain }\end{array}$} \\
\hline & 0 & 1 & 2 \\
\hline $830^{\circ} \mathrm{C}-16 \mathrm{~h}$ & $31(15.5 \%)$ & $169(84.5 \%)$ & 0 \\
\hline $800^{\circ} \mathrm{C}-6 \mathrm{~h}$ & $35(16.5 \%)$ & $177(83.5 \%)$ & 0 \\
\hline $800^{\circ} \mathrm{C}-1 \mathrm{~h}$ & $65(15 \%)$ & $380(85 \%)$ & 0 \\
\hline $800^{\circ} \mathrm{C}-700 \mathrm{~s}$ & $3(3 \%)$ & $104(97 \%)$ & 0 \\
\hline $750^{\circ} \mathrm{C}-6800 \mathrm{~s}$ & $10(7 \%)$ & $147(93 \%)$ & 0 \\
\hline $750^{\circ} \mathrm{C}-700 \mathrm{~s}$ & 0 & $72(100 \%)$ & 0 \\
\hline
\end{tabular}


unlike what was observed in Ref. [15]. The $\alpha_{\mathrm{GB}}$ grain can be in BOR simultaneously with both $\beta$ grains only for some special $\beta / \beta$ GB [29]. No such GB were found in the microstructures analyzed. Table 4 shows that some proportion of the $\alpha_{\mathrm{GB}}$ grains was in BOR with neither of the two adjacent $\beta$ grains (for instance $15 \%$ at $800{ }^{\circ} \mathrm{C}$ and $1 \mathrm{~h}$ ). Similar nonBOR $\alpha_{\mathrm{GB}}$ were reported in studies on Ti-8Al- $x \mathrm{~V}$ [14] and TA6V [16]. This may be due to BOR $\alpha$ formation on TJ followed by non-BOR growth along the GB plane. This interpretation is confirmed by the EBSD maps (no examples are shown here). Table 4 also shows that the proportion increased with exposure time, implying that non-BOR $\alpha_{\mathrm{GB}}$ growth is slower.

The $\alpha_{\mathrm{GB}}$ orientation was often not selected randomly among the 12 potential variants inherited from $\beta$ to $\alpha$ transformation. The present authors studied a VS criterion often discussed in the literature [13-16,23]: If adjacent $\beta$ grains $\beta_{1}$ and $\beta_{2}$ share a common $\{110\}_{\beta}$ pole, the $\alpha_{\mathrm{GB}}$ grain orientation that aligns its $\{0001\}_{\alpha}$ to this common $\{110\}_{\beta}$ pole is often preferentially selected. This means that $\beta_{1}, \beta_{2}$ and $\alpha_{\mathrm{GB}}$ tend to align their dense planes. This VS emphasizes $\alpha_{\mathrm{GB}}$ orientations that are simultaneously in BOR with one $\beta$ grain and not far from the BOR with the other $\beta$ grain.

The purpose in this study was to examine this criterion further by estimating its frequency of occurrence. To this end, an approach introduced recently in Ref. [23] was followed. It consists in measuring for each $\alpha_{\mathrm{GB}}$ grain the angle $\omega$ between the closest $\{110\}_{\beta}$ planes of its two adjacent $\beta$ grains. $\omega$ is different from $\theta$, the misoriention angle. $\omega$ can be close to 0 , even if $\theta$ is large. $\omega=0$ means exact alignment between two $\{110\}_{\beta}$ planes. Then it was determined whether or not the $\alpha_{\mathrm{GB}}$ grain $\{0001\}$ plane was parallel to the closest $\{110\}$ poles.

The result for the $800{ }^{\circ} \mathrm{C}-1 \mathrm{~h}$ and $750{ }^{\circ} \mathrm{C}-700 \mathrm{~s}$ treatments is given in Fig. 4 as a function of $\omega$. The $\beta$ GB were categorized into different classes of $4^{\circ}$ width, according to their $\omega$ values. For each class, the fraction of corresponding $\alpha_{\mathrm{GB}}$ grains satisfying the VS criterion was plotted. As expected and as observed in Ref. [23], for both transformation temperatures the VS frequency decreased with increasing $\omega$ values, that is when the closest $\{110\}_{\beta}$ poles on either side of the GB deviated from alignment. This trend was observed for all other transformation temperatures and durations. It was verified that the $\beta$ grains' orientation distribution was similar for all samples, to avoid any interference from the $\beta$ texture.

A higher driving force and a shorter transformation duration were associated with more frequent VS. This is shown in Table 5 , where the proportion of $\alpha_{\mathrm{GB}}$ that verified the VS criterion is specified for each treatment. For the sake of simplicity, only $\beta / \beta$ GB with $\omega<4^{\circ}$ were considered, at which VS was most frequent. At phase transformation completion (longest durations in Table 5), the VS frequency varied from $36 \%$ at $830{ }^{\circ} \mathrm{C}$ to $45 \%$ at $750{ }^{\circ} \mathrm{C}$. Reducing the transformation duration increased the frequency up to $79 \%$ for $800{ }^{\circ} \mathrm{C}-700$ s treatment. In addition,
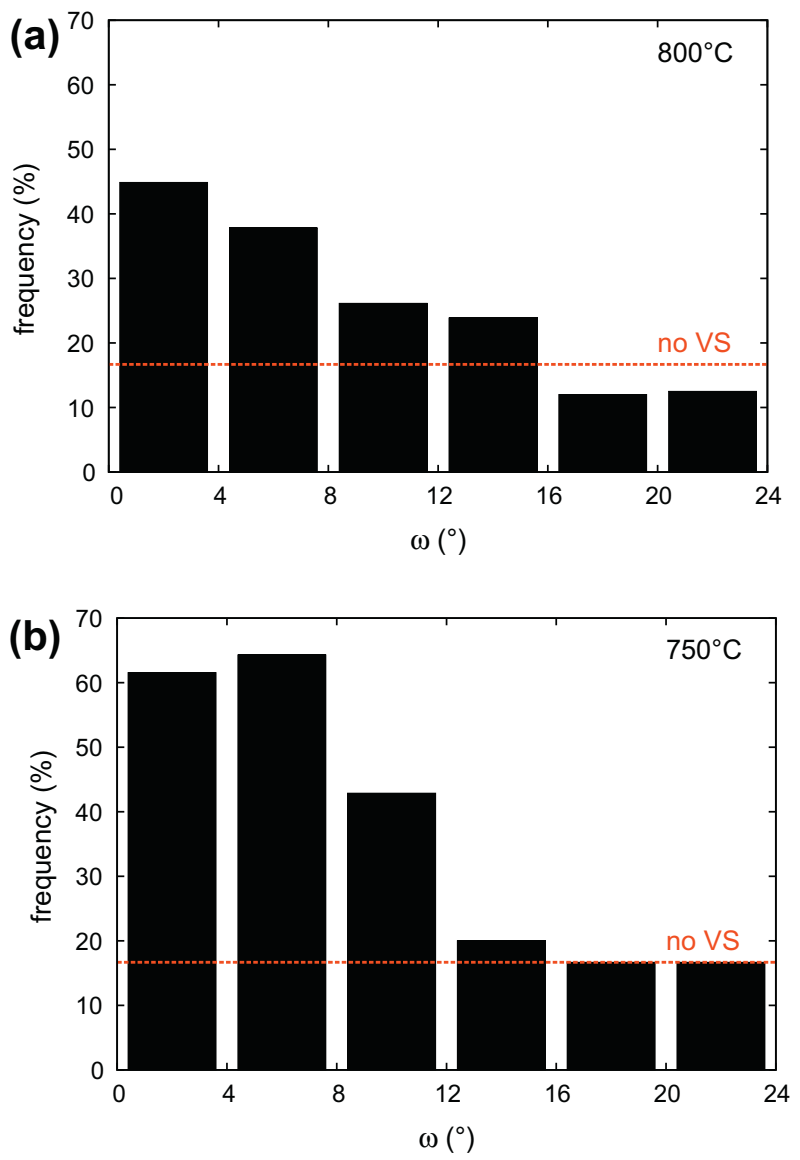

Fig. 4. Proportion of $\alpha_{\mathrm{GB}}$ grains respecting the VS criterion based on the alignment of their $\{0001\} \alpha$ pole with closest $\{110\} \beta$ poles of adjacent $\beta$ grains. The $\beta / \beta$ GB were categorized according to their $\omega$ angle into classes of $4^{\circ}$ range. Each bar indicates the proportion of $\alpha_{\mathrm{GB}}$ grains that respected the VS criterion for each class of $\beta / \beta$ GB.

Table 5

Frequency of VS and $\alpha$ decorated GB proportions as a function of transformation temperature and duration, taking only $\beta / \beta$ GB with $\omega<4^{\circ}$ into account.

\begin{tabular}{|c|c|c|c|c|c|c|}
\hline \multirow{2}{*}{$\begin{array}{l}\text { Temperature } \\
\text { Duration }\end{array}$} & \multicolumn{2}{|c|}{$750^{\circ} \mathrm{C}$} & \multicolumn{3}{|c|}{$800^{\circ} \mathrm{C}$} & \multirow{2}{*}{$\begin{array}{l}830^{\circ} \mathrm{C} \\
16 \mathrm{~h}\end{array}$} \\
\hline & $700 \mathrm{~s}$ & $6800 \mathrm{~s}$ & $700 \mathrm{~s}$ & $1 \mathrm{~h}$ & $6 \mathrm{~h}$ & \\
\hline $\begin{array}{l}\alpha \text { Decorated GB } \\
\text { proportion }(\%)^{\mathrm{a}}\end{array}$ & 81 & 97 & 65 & 81 & 94 & 91 \\
\hline VS frequency (\%) & 61 & 45 & 79 & 45 & 41 & 36 \\
\hline
\end{tabular}

a Total length of $\alpha_{\mathrm{GB}}$ grains divided by total length of $\beta / \beta$ GB.

it enhanced the temperature influence: comparing the $800^{\circ} \mathrm{C}-1 \mathrm{~h}$ and $750{ }^{\circ} \mathrm{C}-700 \mathrm{~s}$ treatments that exhibit the same proportion of GB decoration by $\alpha$, the frequency was $45 \%$ and $65 \%$, respectively. This influence of transformation temperature is confirmed by a previous study on Ti-LCB [23], where a frequency of $70 \%$ was reported at $615^{\circ} \mathrm{C}$, which is equivalent to $705^{\circ} \mathrm{C}$ in Til7 in terms of undercooling $\left(T-T_{\beta}\right)$.

The larger proportion of $\alpha_{\mathrm{GB}}$ verifying the VS criterion at shorter transformation durations is probably due to 
Table 6

Number of $\alpha_{\mathrm{WGB}}$ colonies emitted by $\alpha_{\mathrm{GB}}$ grains at phase transformation completion as a function of transformation temperature.

\begin{tabular}{|c|c|c|c|c|c|c|c|c|c|c|}
\hline \multirow[t]{2}{*}{$T\left({ }^{\circ} \mathrm{C}\right)$} & \multirow[t]{2}{*}{ Duration } & \multirow{2}{*}{$\begin{array}{l}\text { Av. No. of } \alpha_{\mathrm{WGB}} \\
\text { colonies } / \alpha_{\mathrm{GB}}\end{array}$} & \multicolumn{4}{|c|}{$\alpha_{\mathrm{GB}}$ Not verifying VS rule } & \multicolumn{4}{|c|}{$\alpha_{\mathrm{GB}}$ Verifying VS rule } \\
\hline & & & \multicolumn{3}{|c|}{$\begin{array}{l}\text { Proportion of } \alpha_{\mathrm{GB}} \text { per No. of } \\
\alpha_{\mathrm{WGB}} \text { colonies emitted }(\%)\end{array}$} & $\begin{array}{l}\text { Av. No. of } \alpha_{\mathrm{WGB}} \\
\text { colonies } / \alpha_{\mathrm{GB}}\end{array}$ & \multicolumn{3}{|c|}{$\begin{array}{l}\text { Proportion of } \alpha_{\mathrm{GB}} \text { per No. of } \\
\alpha_{\mathrm{WGB}} \text { colonies emitted }(\%)\end{array}$} & $\begin{array}{l}\text { Av. No. of } \alpha_{\mathrm{WGB}} \\
\text { colonies } / \alpha_{\mathrm{GB}}\end{array}$ \\
\hline 750 & $6800 \mathrm{~s}$ & 0.99 & 15 & 85 & 0 & 0.85 & 4 & 66 & 30 & 1.26 \\
\hline 800 & $6 \mathrm{~h}$ & 0.69 & 49 & 50 & 1 & 0.52 & 9 & 81 & 10 & 1.00 \\
\hline 830 & $16 \mathrm{~h}$ & 0.85 & 22 & 77 & 1 & 0.79 & 18 & 64 & 18 & 1.00 \\
\hline
\end{tabular}

more favorable transformation conditions, considering interface and elastic strain energies. Only longer transformation durations would leave enough time for the formation of $\alpha_{\mathrm{GB}}$ with less favorable crystallographic orientations. Another explanation could be that another VS criterion becomes prevalent at longer transformation durations. Such an evolution has been reported in a very different transformation (bainitic ferrite in steel [30]). In fact, another VS criterion for $\alpha$ precipitation on $\beta$ GB in titanium involving the GB plane orientation has been put into evidence in Ref. [17]. Examining the two VS criteria simultaneously would surely provide a more comprehensive understanding. This could also explain why only a certain proportion of the $\alpha_{\mathrm{GB}}$ followed the VS criterion studied when the GB $\omega$ angle was small. These results show that the VS criterion studied in the present work (alignment

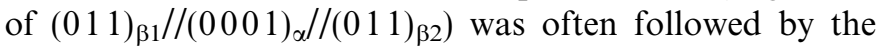
$\alpha_{\mathrm{GB}}$ and at a frequency that depended on transformation temperature and on treatment duration.

Interestingly, more frequent VS at lower transformation temperatures is difficult to explain with the current interpretations of the origin of VS that can be found in the literature. Let us first draw a short overview of these interpretations, focusing on precipitation at GB and diffusion-controlled transformations (not martensitic or massive). In the first studies that put VS in titanium alloys into evidence [16,17], VS has been interpreted qualitatively in the framework of the classical nucleation theory. According to these studies, the variants following VS criteria nucleate more favorably because of a reduced activation energy for critical nucleus formation, due only to $\alpha / \beta$ interfaces with lower interfacial energy. Other analyses considered exclusively the misfit elastic strain energy required to accommodate the $\alpha$ nucleus inside the volume occupied initially by the $\beta$ phase and neglected the influence of interfacial energies (e.g., Ref. [31]). In an experimental study on GB nucleated bainitic ferrite in an $\mathrm{Fe}-9 \mathrm{Ni}-0.15 \mathrm{C}$ steel [30], the effects on VS of both interfacial energies and elastic straining energies were considered simultaneously. Studying the effect of phase transformation duration, it was observed that, at the beginning of the transformation, the variants of bainitic ferrite were restricted to minimize the interfacial energy, while as the transformation proceeded, the VS reducing the deformation energy became more important.
It is thought that none of the results from the literature summarized above can fully account for the increased VS frequency at larger undercooling that was put into evidence in the present work. According to these analyses, increasing the phase transformation chemical driving force could allow less VS because of the larger energy amount available for interfacial energies and elastic energy. Those latter are not expected to depend significantly on temperature (ignoring the effect of plasticity). A thorough investigation of the origin of VS would require a numerical approach considering both interfacial energy and deformation energy with accounting of the neighborhood of the forming grain (i.e., nucleation site $\beta / \beta$ GB plane, but also $\mathrm{TJ}$ or corners $[30,32,33])$. Calculations of the deformation energy should also consider this neighborhood with the anisotropy of the elastic properties and certainly the occurrence of plasticity.

\section{3. $\alpha_{W G B}$ Microtexture and microstructure}

\subsubsection{Microtexture}

The $\alpha_{\mathrm{GB}}$ orientation (and associated VS mechanism) influenced the orientation of the $\alpha_{\mathrm{WGB}}$ colonies that developed from it. Colonies were emitted in one or both $\beta$ grains at each side of the $\alpha_{\mathrm{GB}}$. When only one $\alpha_{\mathrm{WGB}}$ colony was formed, it was always inside the $\beta$ grain in BOR, with $\alpha_{\mathrm{GB}}$ and the $\alpha_{\mathrm{WGB}}$ colony inherited, in this case the exact $\alpha_{\mathrm{GB}}$ orientation, according to EBSD precision, $\sim 1^{\circ}$ or $2^{\circ}$. Only one example (not shown) was observed of an $\alpha_{\mathrm{WGB}}$ colony that did not respect the BOR with its host $\beta$ grain. When $\alpha_{\mathrm{GB}}$ grains emitted a colony in the other $\beta$ grain, it was also in BOR with its respective host $\beta$ grain. This second colony was misoriented from the $\alpha_{\mathrm{GB}}$ by a low angle, always inferior to $5^{\circ}$, but clearly detectable. It seems that the emergence of the $\alpha_{\mathrm{WGB}}$ sideplates inside the $\beta$ grain not in BOR with the parent $\alpha_{\mathrm{GB}}$ was accompanied by partial adaptation of their crystallographic orientation. Interestingly, this adaptation was the same for each sideplate inside the colony. In almost all cases, the variant selected inside the second $\beta$ grain was the one that minimized the misorientation angle between $\alpha_{\mathrm{GB}}$ and $\alpha_{\mathrm{WGB}}$.

It was also found that the $\alpha_{\mathrm{GB}}$ grains that verified the VS criterion studied in Section 3.3.2, i.e., alignment of $\{110\}_{\beta 1},\{0001\}_{\alpha}$ and $\{110\}_{\beta 2}$, had emitted on average more $\alpha_{\mathrm{WGB}}$ colonies than other $\alpha_{\mathrm{GB}}$ (Table 6). For 
instance, at $800{ }^{\circ} \mathrm{C}$ the average number of $\alpha_{\mathrm{WGB}}$ colonies emitted by the $\alpha_{\mathrm{GB}}$ grains was equal to 0.52 for $\alpha_{\mathrm{GB}}$ not following VS and equal to 1.00 for $\alpha_{\mathrm{GB}}$ following VS. The trend was similar for transformation temperatures 750 and $830{ }^{\circ} \mathrm{C}$. Table 6 also shows the proportion of $\alpha_{\mathrm{GB}}$ that emitted 0,1 or $2 \alpha_{\mathrm{WGB}}$ colonies on either side of the GB. The proportion of $\alpha_{\mathrm{GB}}$ with 0 colony was higher inside the population of $\alpha_{\mathrm{GB}}$ that did not follow the VS rule. It can also be seen that almost none $(0-1 \%)$ of the $\alpha_{\mathrm{GB}}$ that did not follow the VS rule emitted two $\alpha_{\mathrm{WGB}}$ colonies, while a significant proportion $(10-30 \%)$ of the $\alpha_{\mathrm{GB}}$ that followed the VS rule emitted two colonies. Finally, a noticeable result was the absence of temperature influence on the number of $\alpha_{\mathrm{WGB}}$ colonies emitted by the $\alpha_{\mathrm{GB}}$.

Two mechanisms may explain why the proportion of $\alpha_{\mathrm{GB}}$ having emitted at least one or even two colonies was much larger inside the population of $\alpha_{\mathrm{GB}}$ that followed the VS criterion. (i) These $\alpha_{\mathrm{GB}}$ formed faster, as concluded in Section 3.3.2; as a result, these $\alpha_{\mathrm{GB}}$ had more time to form colonies. (ii) It is likely that the $\alpha_{\mathrm{GB}}$ verifying $\{110\}_{\beta 1},\{0001\}_{\alpha}$ and $\left\{\begin{array}{llll}1 & 10\end{array}\right\}_{\beta 2}$ alignment reduces the crystallographic orientation adaptation required at the transition from $\alpha_{\mathrm{GB}}$ to $\alpha_{\mathrm{WGB}}$ inside the $\beta$ grain not in BOR with $\alpha_{\mathrm{GB}}$. This is confirmed by the low $\alpha_{\mathrm{GB}} / \alpha_{\mathrm{WGB}}$ misorientation angles reported above. The branching phenomenon has been attributed to either interface instability during growth (e.g., Ref. [34]) or to $\alpha$ sympathetic nucleation at the $\alpha_{\mathrm{GB}} / \beta$ interface [35]. In this latter process, the $\alpha_{\mathrm{GB}} / \beta$ interface is replaced after nucleation by a low angle $\alpha_{\mathrm{GB}} /$ $\alpha_{\mathrm{WGB}}$ boundary, and the sympathetic nucleation rate should be increased for a higher $\alpha_{\mathrm{GB}} / \alpha_{\mathrm{WGB}}$ misorientation angle. Interestingly, the opposite trend was obtained in the present work, since increasing the misorientation angle between $\alpha_{\mathrm{GB}}$ and potential $\alpha_{\mathrm{WGB}}$ platelets seemed to reduce the possibility to emit colonies. Additional characterization of $\alpha_{\mathrm{GB}} / \alpha_{\mathrm{WGB}}$ misorientation should be done at a lower scale using, for example, TEM to investigate further the mechanism of $\alpha_{\mathrm{WGB}}$ sideplate emission.

\subsubsection{Microstructure; number of $\alpha_{W G B}$ colonies per $\beta$ grain}

The average number of $\alpha_{\mathrm{WGB}}$ colonies $\left(N_{\mathrm{WGB}}\right)$ contained by the prior $\beta$ grains is an important microstructure parameter for microtexture and mechanical properties, because each colony represents a potentially large volume of the material where the platelets of the anisotropic $\alpha$ phase exhibit one single orientation. In a previous work [7], $N_{\text {WGB }}$ was measured from SEM micrographs and considering morphological aspects at IT phase transformation completion for the $\beta$-Cez alloy with composition $\mathrm{Ti}-5 \mathrm{Al}$ $4 \mathrm{Mo}-2 \mathrm{Cr}-1 \mathrm{Fe}-4 \mathrm{Zr}-2 \mathrm{Sn}$ (wt.\%), which is close to that of the Ti17 alloy. It was found that $N_{\mathrm{WGB}}$ depended strongly on the transformation temperature, with a value of 7 and 16 for transformation temperatures of 790 and $700{ }^{\circ} \mathrm{C}$, respectively. The larger value of $N_{\mathrm{WGB}}$ at larger undercooling $\left(700^{\circ} \mathrm{C}\right)$ had been ascribed to a larger driving force and a greater number of active nucleation sites for $\alpha_{\mathrm{GB}}$, leading to the formation of more colonies. Indeed, the formation of an $\alpha_{\mathrm{WGB}}$ colony is not possible without the presence of a parent $\alpha_{\mathrm{GB}}$ grain (as the colonies cannot form "directly" on $\beta / \beta$ GB). However, in the previous work, the assumption of a larger density of nucleation sites was not analyzed further.
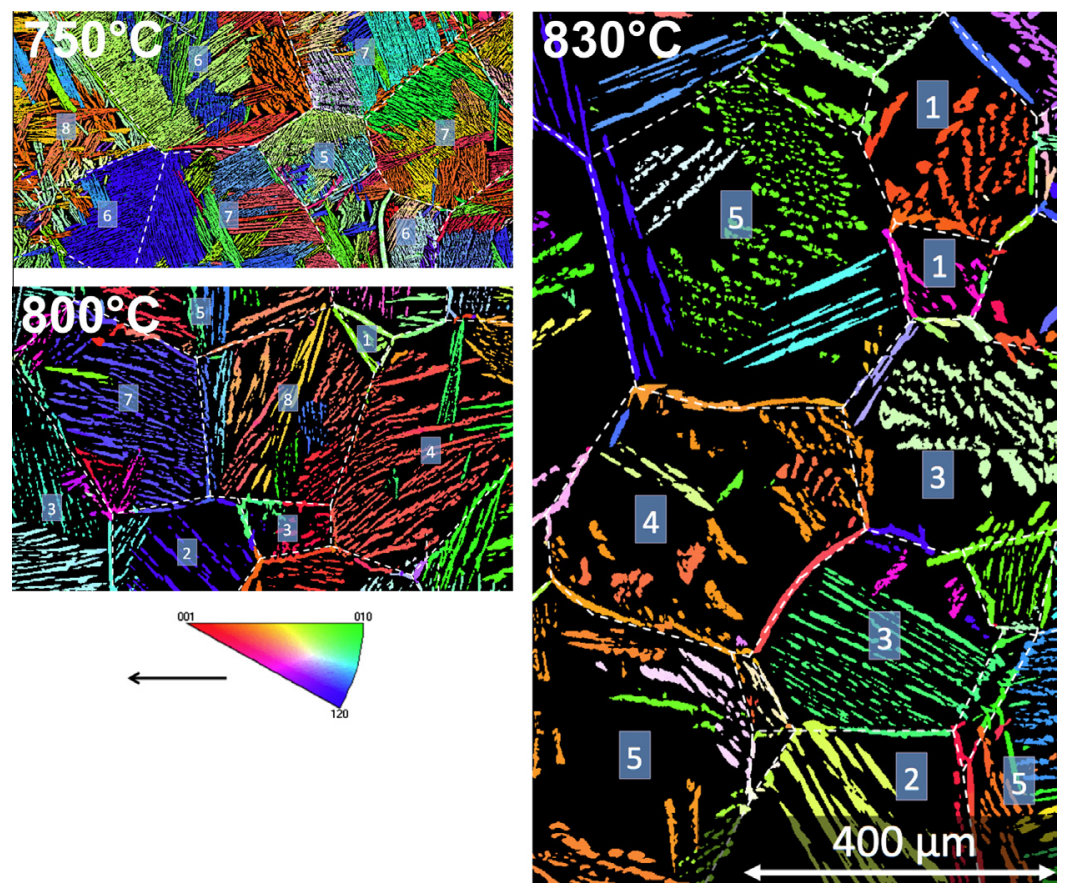

Fig. 5. IPF EBSD maps at the same scale showing the $\alpha$ phase microtexture at phase transformation completion: $750{ }^{\circ} \mathrm{C}-6800 \mathrm{~s} ; 800{ }^{\circ} \mathrm{C}-6 \mathrm{~h} ; 830{ }^{\circ} \mathrm{C}-16 \mathrm{~h}$. $\beta$ phase represented in black, and $\beta / \beta$ GB represented by bold white lines. The $\alpha$ phase pixels are colored according to the color key of the standard triangle. The number of $\alpha_{\mathrm{WGB}}$ colonies inside each $\beta$ grain is indicated. 

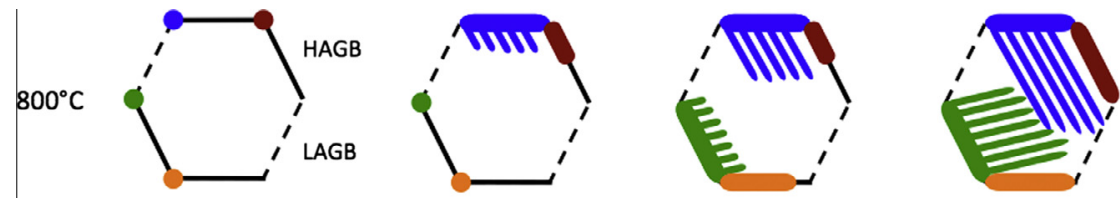

(a) start at TJs
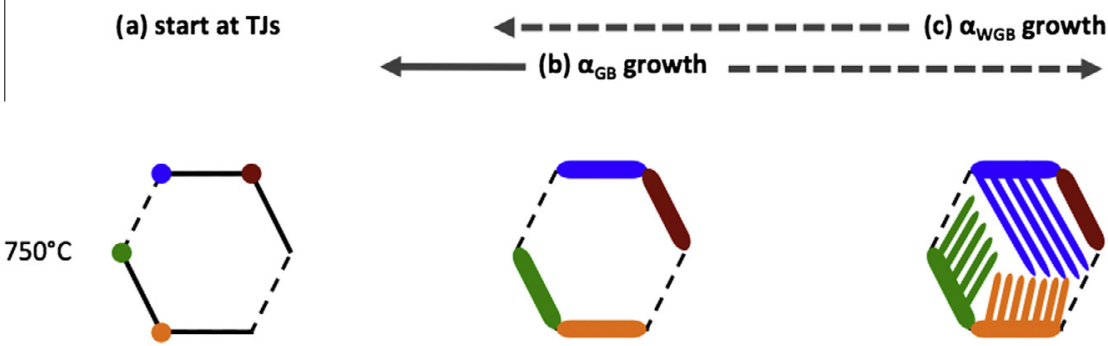

(a) start at TJs

(b) $\alpha_{G B}$ growth

(c) $\alpha_{W G B}$ growth

Fig. 6. Schematic of the $\alpha$ precipitation sequence on $\beta / \beta \mathrm{GB}$ at $800^{\circ} \mathrm{C}$ and $750{ }^{\circ} \mathrm{C}$ according to three consecutive stages: (a) start of $\alpha$ formation at TJ; (b) $\alpha_{\mathrm{GB}}$ growth mostly along HAGB; (c) $\alpha_{\mathrm{WGB}}$ growth inside the $\beta$ grains. At $800^{\circ} \mathrm{C}, N_{\mathrm{WGB}}$ is lower due to slower $\alpha_{\mathrm{GB}}$ formation.

The present results on $\alpha_{\mathrm{GB}}$ and $\alpha_{\mathrm{WGB}}$ allow these observations to be more precise, with counts based on EBSD maps instead of SEM. Fig. 5 shows representative examples of the $\alpha$ phase microtexture at phase transformation completion at 750,800 and $830^{\circ} \mathrm{C}$. The main qualitative observation shown by these EBSD maps is the increase in $N_{\text {WGB }}$ for decreased transformation temperature. The lower amount of $\alpha$ phase at higher temperatures is in accordance with the thermodynamics of this alloy $[2,36]$. A statistical number of such EBSD data were analyzed. Table 3 shows the measured average number of $\alpha_{\mathrm{WGB}}$ colonies per $\beta$ grain $\left(N_{\mathrm{WGB}}\right)$ as well as the number of $\alpha_{\mathrm{GB}}$ grains, their precursors, per $\beta \mathrm{GB}\left(N_{\mathrm{GB}}\right)$, for phase transformation completion at 750,800 and $830^{\circ} \mathrm{C} . N_{\mathrm{GB}}$ and $N_{\mathrm{WGB}}$ increased with decreasing temperature from 830 to $750{ }^{\circ} \mathrm{C}: N_{\mathrm{GB}}$ by a factor of 1.3 , and $N_{\mathrm{WGB}}$ by a factor 2.1. This result is in accordance with Ref. [7]. However, according to the small $N_{\mathrm{GB}}$ variation, the $N_{\mathrm{WGB}}$ increase cannot simply be explained by a larger number of available precursor $\alpha_{\mathrm{GB}}$ per $\beta$ grain. Neither can this be explained by more frequent emission of $\alpha_{\mathrm{WGB}}$ colonies by $\alpha_{\mathrm{GB}}$, as shown in the previous section.

A probable explanation for the larger $N_{\mathrm{WGB}}$ at lower transformation temperature is schematized in Fig. 6. One has to compare the detailed evolution of the microstructure at 800 and $750{ }^{\circ} \mathrm{C}: \alpha_{\mathrm{GB}}$ nucleation, growth and emission of $\alpha_{\mathrm{WGB}}$ colonies. The difference between the two temperatures is the kinetics of $\alpha_{\mathrm{GB}}$ formation and the $\alpha_{\mathrm{WGB}}$ growth stage. Fig. 6 illustrates the consequence at $800{ }^{\circ} \mathrm{C}$. The slow kinetics of $\alpha_{\mathrm{GB}}$ formation will lead to a limited number of $\alpha_{\mathrm{WGB}}$ colonies that start to grow while some $\alpha_{\mathrm{GB}}$ are still growing. The predominant growth of these first colonies will prevent other colonies from forming by occupying the $\beta$ grain, and this will reduce $N_{\text {WGB }}$. In contrast, at $750{ }^{\circ} \mathrm{C}$, the kinetics of $\alpha_{\mathrm{GB}}$ formation is more rapid, leading to earlier simultaneous growth of $\alpha_{\mathrm{WGB}}$ on existing $\alpha_{\mathrm{GB}}$. More colonies will be able to grow in the parent $\beta$ grain, resulting in final larger $N_{\mathrm{WGB}}$. Table 7 illustrates the differences between the duration of $\alpha_{\mathrm{GB}}$ and $\alpha_{\mathrm{WGB}}$ growth stages. These durations, estimated as the time necessary to fill $80 \%$ of the GB by $\alpha_{\mathrm{GB}}$ grains (see Section 3.1.2) and to fill $100 \%$ of the $\beta$ grains by $\alpha_{\mathrm{WGB}}$ colonies (estimated from previous studies on kinetics [19-21]), respectively, are summarized as follows. It can be seen that, at $750{ }^{\circ} \mathrm{C}$, the time necessary to fill the GB by $\alpha_{\mathrm{GB}}$ nucleation and growth is seven times greater than the time for one colony to grow over the grain, while this time is 18 times greater at $800{ }^{\circ} \mathrm{C}$. It can be mentioned that these times are dependent on the $\beta$ grain size: i.e., for a large grain size, the time necessary for $\alpha_{\text {WGB }}$ to fill the grain will increase, allowing other colonies to grow.

\section{Summary and discussion}

In this contribution, microstructure and microtexture evolution during IT $\beta \rightarrow \alpha$ phase transformation was studied in the Ti17 $\beta$-metastable alloy with undercooling of $50{ }^{\circ} \mathrm{C}, 80^{\circ} \mathrm{C}$ and $130{ }^{\circ} \mathrm{C}\left(T=830,800\right.$ and $\left.750{ }^{\circ} \mathrm{C}\right)$, using

Table 7

Approximate duration to fill the GB with $\alpha_{\mathrm{GB}}$ grains and the $\beta$ grains with $\alpha_{\mathrm{WGB}}$ colonies.

\begin{tabular}{lll}
\hline Growth stage duration & $750{ }^{\circ} \mathrm{C}$ & $800{ }^{\circ} \mathrm{C}$ \\
\hline$\alpha_{\mathrm{GB}}$ & $<700 \mathrm{~s}$ & $<3600 \mathrm{~s}$ \\
$\alpha_{\mathrm{WGB}}$ & $\sim 100 \mathrm{~s}$ & $\sim 200 \mathrm{~s}$ \\
$\alpha_{\mathrm{WGB}} / \alpha_{\mathrm{GB}}$ Stage duration ratio & $\sim 7$ & $\sim 18$ \\
\hline
\end{tabular}


EBSD and conventional microscopy. Emphasis was put on examining $\alpha$ precipitation at $\beta / \beta$ GB. The precipitation sequence and the influence of transformation temperature, schematized in Fig. 6, can be summarized as follows: $\alpha$ formation starting at TJ and/or QP followed by $\alpha_{\mathrm{GB}}$ growth along the $\beta / \beta$ GB planes, then growth of $\alpha_{\mathrm{WGB}}$ colonies inside the $\beta$ grains at a slower rate than $\alpha_{\mathrm{GB}}$. New observations regarding this sequence were the following.

(1) The number of $\alpha_{\mathrm{GB}}$ grains per $\beta / \beta \mathrm{GB}$, which was limited to a value of $\sim 2$, did not vary significantly with the transformation temperature. The $\alpha_{\mathrm{GB}}$ formation started at $\beta$ TJ.

(2) The $\alpha_{G B}$ formation was faster at lower transformation temperatures. $\alpha_{\mathrm{GB}}$ growth was faster on high angle GB (misorientation angle $\theta>15^{\circ}$ ).

(3) As observed in Ref. [7], the number of $\alpha_{\mathrm{WGB}}$ colonies per prior $\beta$ grain was larger at lower transformation temperatures: 7.7 at $750{ }^{\circ} \mathrm{C}, 4.4$ at $800{ }^{\circ} \mathrm{C}$ and 3.6 at $830^{\circ} \mathrm{C}$. The present study showed that this was a consequence of faster $\alpha_{\mathrm{GB}}$ formation at lower temperatures.

(4) The $\alpha_{\mathrm{GB}}$ orientations frequently followed an already established VS criterion based on the alignment of $\left(\begin{array}{lll}0 & 1 & 1\end{array}\right)_{\beta 1},\left(\begin{array}{llll}0 & 0 & 0 & 1\end{array}\right)_{\alpha}$ and $\left(\begin{array}{llll}0 & 1 & 1\end{array}\right)_{\beta 2}$ planes. New observation is that the VS frequency following this criterion was higher at a lower transformation temperature and shorter transformation duration.

(5) Many $\alpha_{\mathrm{GB}}$ grains that followed the VS criterion (10 $30 \%$ ) emitted two $\alpha_{\mathrm{WGB}}$ colonies on either side of the $\beta / \beta$ GB: not only into the $\beta$ grains in BOR with $\alpha_{\mathrm{GB}}$, but also into the other $\beta$ grains without or with $\alpha_{\mathrm{GB}}$. In contrast, $\alpha_{\mathrm{GB}}$ without particular orientation almost never emitted one colony into the non-BOR adjoining $\beta$ grains.

(6) The $\alpha_{\text {WGB }}$ colonies were always in BOR with their host $\beta$ grains, as already observed. The present study showed that colonies forming inside the non-BOR $\beta$ grains were misoriented from their precursor $\alpha_{\mathrm{GB}}$ grain by an angle of nearly $5^{\circ}$, while colonies forming inside the $\beta$ grains in $\mathrm{BOR}$ with $\alpha_{\mathrm{GB}}$ inherited its exact orientation, with the precision of EBSD measurement.

The purpose of these observations was to examine the influence of the transformation temperature on the microtexture development associated with $\alpha$ precipitation at $\beta / \beta$ GB. Interpreting the $\alpha$ microtexture at the scale of the prior $\beta$ grains in terms of the average number of $\alpha$ orientations per $\beta$ grain and considering their orientations, the main conclusion is that decreasing the transformation temperature tends to weaken the $\alpha$ microtexture, because of more $\alpha_{\mathrm{WGB}}$ colonies forming inside the $\beta$ grains, thus increasing the number of $\alpha$ orientations. Each colony is associated with one specific orientation, according to the observations. As mentioned above, the number of colonies varied from 3.6 when transformation occurred at $830{ }^{\circ} \mathrm{C}$ to 7.7 when transformation occurred at $750{ }^{\circ} \mathrm{C}$. The dominant factor controlling the microtexture was the variation in number of colonies, although VS occurred extensively, often making the individual orientation of the colonies depend on the crystallographic parameters of the $\beta / \beta$ GB from which they emanated. If decreasing the transformation temperature increased the frequency of VS occurrence (from $36 \%$ at $830^{\circ} \mathrm{C}$ to $45 \%$ at $750{ }^{\circ} \mathrm{C}$, at phase transformation completion, at $\beta / \beta$ GB with $\omega<4^{\circ}$ ), the quantitative effect was not significant enough to expect noticeable $\alpha$ microtexture strengthening compared with the number of $\alpha_{\mathrm{WGB}}$ colonies variations. It can be mentioned that a similar limited effect of VS has been put into evidence recently in Ref. [37], but considering the macroscopic $\alpha$ phase transformation texture instead of the microtexture. In this study, the authors made the prior $\beta$ grain texture vary, and they showed that the $\alpha$ phase transformation texture was more controlled by this parameter than by the occurrence of VS.

In addition, the present study showed that, to understand the formation of the microtexture associated with $\alpha_{\mathrm{WGB}}$ colonies, one has to examine their precursors, i.e., the $\alpha_{\mathrm{GB}}$ grains that form at early stages of precipitation. By studying the kinetics of $\alpha_{\mathrm{GB}}$ formation, it was found that the increased number of colonies at a lower transformation temperature was due to the more rapid $\alpha_{\mathrm{GB}}$ formation along the $\beta / \beta$ GB compared with the growth rate of $\alpha_{\mathrm{WGB}}$. One notable finding was to clarify the common interpretation, based on enhanced nucleation. Focusing on $\alpha_{\mathrm{GB}}$ grains was also necessary in order to study VS, because the $\alpha_{\text {WGB }}$ colonies cannot form directly on $\beta / \beta$ GB. A striking result was the more frequent occurrence of VS at shorter transformation duration and increased undercooling. Current interpretations of VS in the literature did not make it possible to explain this trend satisfactorily. Probably, the energy barrier associated with $\alpha_{\mathrm{GB}}$ with favorable orientations is lower. Numerical simulations will help in further analyses of VS for heterogeneous $\alpha$ precipitation at $\beta / \beta$ GB. The other result was the more frequent emission of $\alpha_{\mathrm{WGB}}$ colonies by $\alpha_{\mathrm{GB}}$ that followed the VS criterion. As a result, a large proportion of the $\alpha$ phase emanated from $\beta / \beta$ GB with close $\left(\begin{array}{llll}0 & 1 & 1\end{array}\right) \beta 1$ and (0 11 1) $\beta 2$ planes.

Finally, it may be emphasized that some observations in the present study should not be generalized too fast if one is considering a titanium alloy with a chemical composition different from that of Ti17. Depending on the alloy composition, the nucleation of $\alpha$ may be possible at the middle of GB instead of being restricted to TJ and/or QP. This would modify the $\alpha_{\mathrm{GB}}$ formation sequence from the beginning, compared with the sequence that the present authors observed. The VS frequency of occurrence as a function of temperature and exposure time also probably depends on the alloy composition, as it was shown that it depends on the transformation driving force. The prior $\beta$ grain size also is an important parameter, as it influences the number of $\alpha_{\mathrm{WGB}}$ colonies per $\beta$ grain. 


\section{Conclusion}

The transformation temperature influence on the $\alpha$ microtexture development associated with the $\alpha$ precipitation at $\beta / \beta$ GB in the near $\beta$ Til7 alloy was studied using EBSD. By interpreting the $\alpha$ phase microtexture at the scale of prior $\beta$ grains $(\sim 200 \mu \mathrm{m})$, it was found that, for the alloy studied and the temperature range considered, decreasing the transformation temperature decreased the microtexture strength because of a greater number of $\alpha_{\mathrm{WGB}}$ colonies, each colony increasing by one the number of $\alpha$ orientations inside the $\beta$ grains. The greater number of colonies was due to faster formation of their precursors, the $\alpha_{\mathrm{GB}}$ grains, as revealed by a detailed examination of their formation. $\alpha_{\mathrm{GB}}$ crystallographic orientations followed extensively a VS criterion based on the alignment of $\left(\begin{array}{llll}0 & 1 & 1\end{array}\right)_{\beta} / /\left(\begin{array}{llll}0 & 0 & 0 & 1\end{array}\right)_{\alpha \mathrm{GB}} / /\left(\begin{array}{lll}0 & 1 & 1\end{array}\right)_{\beta}$. From a statistically relevant number of observations, VS was found to be more frequent at a lower transformation temperature, but the effect was not significant enough to influence the $\alpha$ microtexture, at the scale of one single prior $\beta$ grain. The $\alpha_{\mathrm{GB}}$ precursors that followed the VS criterion emitted on average more $\alpha_{\mathrm{WGB}}$ colonies than those without particular orientation. Only such $\alpha_{\mathrm{GB}}$ grains emitted two colonies on either side of the $\beta / \beta$ GB. As a result, a large proportion of the $\alpha_{\mathrm{WGB}}$ colonies (but not all) emanated from $\beta / \beta$ GB with close (0 111$) \beta 1 / /\left(\begin{array}{llll}0 & 1 & 1\end{array}\right) \beta 2$.

\section{Acknowledgements}

CNRS and Lorraine Regional Council are gratefully acknowledged for funding of this work and Snecma (Safran) for providing Til7 alloy.

\section{References}

[1] Aeby-Gautier E, Bruneseaux F, Da Costa Teixeira J, Appolaire B, Geandier G, Denis S. J Mater 2007;59:54.

[2] da Costa Teixeira J, Appolaire B, Aeby-Gautier E, Denis S, Cailletaud G, Späth N. Mater Sci Eng A 2007;448A:135.

[3] Bruneseaux F, Aeby-Gautier E, Geandier G, Da Costa Teixeira J, Appolaire B, Weisbecker P, et al. Mater Sci Eng A 2008;476:60.

[4] Menon ESK, Aaronson HI. Metall Trans A 1986;17A:1703.

[5] Angelier C, Bein S, Béchet J. Metall Trans A 1997;28A:2467.

[6] Laude E, Gautier E, Denis S. Titanium '95. vol. III. Birmingham; RU; 22-26 October 1995. p. 2330-7, 1996.
[7] Laude E, Gautier E, Archambault P, Denis S. Rev Métall CIT 1996;93:1067.

[8] Gheorge M, Qazi JI, Rack HJ. Titanium-science and technology, 13-18 July 2003, vol. 2. Hamburg: DGM; 2004. p. 1155-61.

[9] Fujii H, Suzuki HG. In: Sixth world conference on titanium. III. Cannes, 6-9 June 1988. p. 1489-94.

[10] van Bohemen SMC, Sietsma J, van der Zwaag S. Phys Rev B 2006;74:134114.

[11] Gey N, Humbert M. Acta Mater 2002;50:277.

[12] Germain L, Gey N, Humbert M, Vo P, Jahazi M, Bocher P. Acta Mater 2008;56:4298.

[13] Bhattacharyya D, Viswanathan GB, Denkenberger R, Furrer D, Fraser HL. Acta Mater 2003;51:4679.

[14] Banerjee R, Bhattacharyya D, Collins PC, Viswanathan GB, Fraser HL. Acta Mater 2004;52:377.

[15] Bhattacharyya D, Viswanathan GB, Fraser HL. Acta Mater 2007;55:6765.

[16] Stanford N, Bate PS. Acta Mater 2004;52:5215.

[17] Furuhara T, Takagi S, Watanabe H, Maki T. Metall Trans A;27A:1635.

[18] da Costa Teixeira J, Appolaire B, Aeby-Gautier E, Denis S, Héricher L. Comput Mater Sci 2008;42:266.

[19] Appolaire B, Héricher L, Aeby-Gautier E. Acta Mater 2005;53:300.

[20] da Costa Teixeira J, Appolaire B, Aeby-Gautier E, Denis S, Bruneseaux F. Acta Mater 2006;54:4261.

[21] Di Napoli P, Appolaire B, Aeby-Gautier E, Beneteau A. Solid State Phenomena 2011;172-174:1044.

[22] Chaussy F. PhD thesis, INPG, Grenoble; 1996.

[23] van Bohemen SMC, Kamp A, Petrov RH, Kestens LAI, Sietsma J. Acta Mater 2008;56:5970

[24] Lee E, Banerjee R, Kar S, Bhattacharyya D, Fraser HL. Philos Mag 2007;87(24):3615.

[25] Bache MR, Cope M, Davies HM, Evans WJ, Harrison G. Int J Fatigue 1997;19(Suppl. 1):S83-8.

[26] Sargent GA, Kinsel KT, Pilchak AL, Salem AA, Semiatin SL. Metall Trans A 2012;43A:3570.

[27] da Costa Teixeira J. PhD thesis, INPL, Nancy; 2005.

[28] Sharma H, van Bohemen SMC, Petrov RH, Sietsma J. Acta Mater 2010;58:2399.

[29] Germain L, Gey N, Humbert M. Ultramicroscopy 2007;107:1129.

[30] Furuhara T, Kawata H, Morito S, Miyamoto G, Maki T. Metall Trans A 2008;39A:1003.

[31] Humbert M, Germain L, Gey N, Bocher P, Jahazi M. Mater Sci Eng A 2006;430:157-64.

[32] Zhang GH, Takeuchi T, Enomoto M, Adachi Y. Metall Trans A 2011;42A:1597.

[33] Lischewski I, Gottstein G. Acta Mater 2011;59:1530.

[34] Townsend RD, Kirkaldy JS. Trans ASM 1968;61:605.

[35] Menon ESK, Aaronson HI. Acta Metall 1987;35:549.

[36] Héricher L. PhD thesis, INPL, Nancy, France; 2004.

[37] Obasi GC, Birosca S, Leo Prakash DG, Quinta da Fonseca J, Preuss M. Acta Mater 2013;60:6013. 